\title{
Novel Methotrexate-Loaded Zein Nanoparticles With Improved and Extended Biopharmaceutical Performance: QbD-Steered Development, and Extensive In Vitro and In Vivo Evaluation
}

\author{
Atul Jain \\ Panjab University Faculty of Pharmaceutical Sciences \\ Teenu Sharma \\ Panjab University Faculty of Pharmaceutical Sciences \\ Rajendra Kumar \\ Panjab University Faculty of Pharmaceutical Sciences \\ Sumant Saini \\ Panjab University Faculty of Pharmaceutical Sciences \\ Jasleen Kaur \\ Panjab University \\ OP Katare \\ Panjab University Faculty of Pharmaceutical Sciences \\ Bhupinder Singh Bhoop ( $\square$ bsbhoop@yahoo.com ) \\ University Institute of Pharmaceutical Sciences, Panjab University
}

\section{Research Article}

Keywords: Breast Cancer, Cell culture, Pharmacokinetics, Design of Experiments (DoE), polymeric nanoparticles

Posted Date: September 13th, 2021

DOI: https://doi.org/10.21203/rs.3.rs-850909/v1

License: () (i) This work is licensed under a Creative Commons Attribution 4.0 International License. Read Full License 


\section{Abstract}

The current work entails QbD-enabled preparation of methotrexate-loaded nanoparticles (NPs) using zein as the releasecontrolling natural polymer. Initially, quality risk estimationand factor screening studies using Taguchi design were undertaken to delineate "vital few" process and material attributes among "plausible so many". Further, formulation optimization using central composite design and validation using correlation plots and percent predictive bias was carried out. Optimized NPs exhibited mean size of $159 \mathrm{~nm}$, zeta potential of $14.85 \mathrm{mV}$ and entrapment of $50.23 \%$. In vitro dissolution kinetic modelling unearthed non-Fickian drug release extension mechanism from the proposed zein NPs. In vitro MTT and apoptosis assay using MCF-7 cells and cellular uptake studies using Caco-2 cells indicate remarkably superior anticancer potential of zein NPs over pure methotrexate, ascribable to their nanometric size and cationic nature. In vivo pharmacokinetic studies in rat construed significant enhancement by 2.15-fold in $\mathrm{AUC}_{48 \mathrm{~h}}(\mathrm{p}<0.001), 1.30$-fold in $\mathrm{C}_{\max }(\mathrm{p}<0.05), 3.67$-fold in $\mathrm{T}_{\max }(\mathrm{p}<0.001)$, and 1.38-fold in $T_{1 / 2}(p<0.01)$, along with notably reduced variability in biopharmaceutical performance. Establishment of significant point-topoint level A in vitro/ in vivo correlations (IVIVC) and kinetic modeling construed the robustness and prognostic ability of drug release studies. Robustness of the nanoformulation was ratified under refrigerated storage through six months'stability studies. Overall, the studies unequivocally indicate development of a stable nanoparticulate formulation with significantly enhanced extent, extension and consistency of biopharmaceutical performance, along with improved anticancer potential of methotrexate.

\section{Introduction}

Cancer, a proliferative syndrome, has proved to be serious threat to human health and life, since decades [1]. Breast cancer, in particular, has been the primary cause of deaths in women, with approximately 2.1 million new cases reported every yearacross the globe [2, 3]. Methotrexate (MTX), in this regard, plays a vital role in the therapeutic management of cancers [4]. Exhibiting poor water solubility $(0.01 \mathrm{mg} / \mathrm{mL}$ ) couple with poor permeability (cLog P of 0.53 ), it can safely be categorizedas a Class IV drugas per Biopharmaceutical Classification System (BCS) [5]. Reported to follow saturable absorption through proximal intestine,mediated through specific transporters, MTX shows dose-dependent oral bioavailability [6, 7]. Accordingly, lower doses of MTX have been observed to demonstrate relatively higher oral bioavailability [8,9]. Besides, owing to its poor solubility and permeability, coupled withsaturation of transporters, MTX is documented to exhibit inconsistent pharmacokinetic behaviour and erratic bioavailability $[10,11]$. As MTX is also known to observe a narrow therapeutic index, it is highly recommended to maintain and sustain plasma levels of drug at the optimal levels $[12,13]$.

Myriad types of nanostructured delivery systems of MTX, in this context, have been explored not only for improving its extent of bioavailability, but also in reducing the intensity and frequency of undesirable side effects like nephrotoxicity, bone marrow suppression, chronic interstitial obstructive pulmonary disease and hepatotoxicity [4, 14]. Sustained drug release characteristics has been another distinct advantage of employing such nanocarriers in drug delivery [15]. Drug delivery systems, like liposomes [16], microcapsules [17], synthetic polymer-based NPs [4, 18], lipid-based non-vesicular drug delivery systems like solid lipid nanoparticles (SLNs) [19, 20], and lipid-polymer hybrid NPs [21], have been explored to improve the biopharmaceutical potential of MTX and/or controlled release characteristics, but with limited fruition. Many of such nanocarrier systems also tend to pose serious problems ofinept robustness and stability, and rapid degradation in the gastric milieu [22].

Recently, the domain of drug delivery has witnessed growing popularity of diverse polymers obtained from natural origin [23]. Zein, a natural, water-insoluble and prolamine-based amphiphilic cationic polymer, has duly been approved by the United States Federal Drug Agency as Generally Regarded as Safe (GRAS) [24]. It is a plant protein, derived usually from maize, which has found myriad uses as a wrapping material in food industries, primarily due to its capability to sustain moisture levels in prepared goods [24]. Because of its high coating capacity, coupled with low cost, biocompatibility and biodegradability, zein has also been successfully employed for developing modified release systems for the delivery of diverse drugs $[25,26]$, enzymes [27, 28], essential oils [29] and other substances [30,31]. 
Systematic drug delivery system development to provide the required quality traits, while optimizing different possible process and material parameters, is a formidable task. This could be achieved using Quality by Design (QbD) paradigms, involving the cardinal principles of Quality Risk Management (QRM) and Design of Experiments (DoE) [32, 33]. Thus, the present work envisages organized development, characterization and evaluation of MTX-encapsulated NPs for attaining improved, sustained and consistent biopharmaceutical attributes of the drug. Zein was selected to formulate such MTX-loaded NPs for efficient and cost-effective controlled drug delivery to potentially facilitate effective drug transportation to the target cells [34].

\section{Materials}

MTX was obtained from IPCA Laboratories, Mumbai, India, as a gift drug sample. Zeinwasprocured fromAcros organics, Thermo Fisher Scientific, New Jersey, USA, while 3-(4,5-dimethylthiazol-2-yl)-2,5-diphenyltetrazolium bromide (MTT) and Annexin V-FITC apoptosis kit were procured from Sigma Aldrich, Missouri, USA,and BD Bioscience, New Jersey, USA, respectively. MCF-7 breast cancer and Caco-2 intestinal epithelial barrier model cells were arranged from National Centre of Cell Science, Pune, India. Different other laboratory excipients, reagents and solvent of pure analytical grade were used without any further alteration throughout the study.

\section{Methods}

\subsection{Preparation of Polymeric Nanoparticles}

Zein-based NPs encapsulating MTX were formulated using an already reported evaporation method, after minor modifications [4, 32, 35]. Briefly, zein was dissolved in ethanol ( $90 \% \mathrm{v} / \mathrm{v})$, constituting the organic phase, while phosphate buffer saline (i.e., PBS, pH 7.4), containing the requisite amounts of MTX and Pluronic F-68 (PF-68) as the stabilizer, constituted as the aqueous phase. The aforesaid organic phase was added into the aqueous phase, drop-wise, with constant stirring, employing a magnetic stirrer (REMI, Mumbai, India) to allow the diffusion and evaporation of organic phase, and eventually, the formation of colloidal dispersion of zein NPs.

\subsection{QTPP and CQAs}

As per QbD approach, the quality target product profile (QTPP) for the proposed polymeric nanocarriers was firstly embarked upon with an aim to improve the quality attributes of zein NPs [36]. Different critical quality attributes (CQAs), like mean particle size (PS), zeta potential (ZP) and \% entrapment efficiency (EE), were identified, and plausible cause-effect relationships among the chosen CQAs and probable method or material parameters were delineated using an Ishikawa fish-bone diagram.

Consequently, an initial risk estimation matrix (REM) exercise involving all the potential factors influencing the QAs (PS, ZP and $\%$ EE) was conducted by assigning these to low, medium and high levels of risk [37-39].

\subsection{Factor Screening Studies}

Design Expert ${ }^{\circledR}$ software package (Version 11, Stat-Ease Inc., Minnesota,USA) was used to implement Taguchi design (TgD) with a seven-variable eight-run matrix in order to chalk out highly influential method and material parameters. Only the high- and medium-risk factors, previously identified using REM studies in Section 3.2, were considered for factor screening. Table 1 enlists the design matrix for various variables screened, along with their high and low levels, respectively [33, 40].

\subsection{Optimization Studies on Zein NPs}

The CMPs, i.e., amount of polymer $\left(\mathrm{X}_{1}\right)$ and percentage of surfactant $\left(\mathrm{X}_{2}\right)$, were systematically optimized using a nonlinear second-order central composite design (CCD). Table 2 summarises the design matrix, consisting of a total of thirteen experimental trials, along with pertinent factors and their corresponding levels.

\subsubsection{Modelling data analysis, validation and optimum search}


Subsequently, in order to fit the experimental data, a quadratic polynomial model was employed to optimize data analysis and model validation. Model evaluation was carried out using Pearson's correlation coefficient (R) and lack-of-fit analysis. The 2Dcontour plots and 3D-response surfaces were drawn and deciphered for ostensible factor-response relationship(s). Optimal solution was selected using mathematical desirability function by "trading-off" different CQAs, and subsequentlyby graphical optimization, delineating the "design space"region by following the criteria of maximal values of \% EE and ZP, and minimal values of PS and \% cumulative drug release. Six confirmatory formulations were prepared as the validation runs (ZNP 1-6) to evaluate the predictive ability of the evolved polynomial models and DoE methodology, using percentage of prediction error (\%PPE) and linear correlation plots.

\subsection{Characterization of Zein NPs}

\subsubsection{Mean Particle sizeand Zeta Potential}

The magnitudes of meanparticle size as well as of zeta potential of the prepared NPs were measured at $25^{\circ} \mathrm{C}$ using a particle size analyser, (Zetasizer, ZS90; Malvern Instruments, UK). Dispersion of zein NPs was placed into a micro-electrophoreticcell, fixed at an angle of $90^{\circ}$.

\subsubsection{Field Emission Scanning Electron Microscopy (FESEM)}

Surface morphology of optimized NPs was examined using an FESEM system (SU-8010, Hitachi,Tokyo, Japan). A droplet of sample was coated with gold, and the microphotographs were captured at suitable operating conditions.

\subsubsection{Transmission electron microscopy (TEM)}

The prepared optimized formulation was further characterized employing TEM (Tecnai, Holland, Netherland), operating at suitable accelerating voltage. A droplet of sample was placed on a grid surface, followed by (negative) staining with $1 \%$ phosphotungustic acid. Following air-drying, the grid was exposed for imaging and the microphotographs were taken at appropriate magnification(s).

\subsubsection{Encapsulation efficiency}

The values of \% EE of the prepared zein NPs were obtained by adopting a reported method [41, 42]. Briefly, $2 \mathrm{~mL}$ aliquots of the optimized prepared formulation were centrifuged (Sorvall ${ }^{\mathrm{TM}}$ legend ${ }^{\mathrm{TM}}$ XTR, Thermo Fisher Scientific, Massachusetts, USA) at $10,000 \mathrm{rpm}(11,200 \mathrm{~g})$ for10 minutes, and free drug in the supernatant was estimated at a $\lambda_{\max }$ of $257 \mathrm{~nm}$ using a UV-Vis spectrophotometer (UV $3000^{+}$, Labindia, Mumbai, India).

\subsubsection{In vitrodrug release studies}

Drug release kinetics from the optimized NPswas investigated employing the dialysis bag (MWCO 10-12, KD, Himedia) method $[43,44]$. Two millilitres of suspensions, each of the drug and its optimized NPs, were placed into the dialysis bag(s) and suspended in the receptor compartment constituting phosphate buffer $(\mathrm{pH}$ 7.4: $50 \mathrm{~mL}$ ) over a water bath (Rivotek, Mumbai, India), maintained at $37^{\circ} \mathrm{C}$. At regular intervals, $2 \mathrm{~mL}$ aliquots each of medium were with drawn and replaced with fresh solvent inequal volumes at pre-determined time intervals during the study. Quantification of MTX was carried out employing UV spectrophotometry. Drug release data were subsequently fitted into various different kinetic models to arrive at the possible mechanism(s) of MTX release from the prepared NPs.

\section{6/n VitroCell Culture Studies}

Cells were harvested and grown in a tissue culture flask $\left(25 \mathrm{~cm}^{2}\right)(\mathrm{BD}$, Falcon, New Jersey,USA), according to the requisite guidelines [45]. Later, the cells were passaged to an alternate flask, as per the standard protocol for in vitro cell culture studies [46].

\subsubsection{MCF-7 Cell culture investigations}

Page $4 / 23$ 


\subsubsection{MTT cellularviability studies}

Cell viability assay using free MTX and the prepared zein NPs was conducted employing an MTT assay on the MCF-7 cells, according to the procedure already reported by us $[32,47,48]$. Harvested cells $\left(1 * 10^{5} \mathrm{cells} /\right.$ well) were seeded in a 96 -well plateand were kept for adherence to the flask surface. Free MTX and zein NPs containing equivalent amount drug amounts were added in serial concentrations, and kept aside for incubationat $37 \pm 1^{\circ} \mathrm{C}$ under $\mathrm{CO}_{2}(5 \%)$ environment. Subsequently, excess of zein NPs, free MTX and medium were removed, and washed with buffer (PBS; pH 7.4). Optical density (OD) was measured at $550 \mathrm{~nm}$ employing an ELISA plate reader (Multiscan ${ }^{\mathrm{TM}}$ FC microplate, Thermo Fisher Scientific ${ }^{\mathrm{TM}}$, New Jersey, USA), and percentage of cell viability was quantified.

\subsubsection{Apoptosisassay}

Apoptosis assay using MCF-7 cells was carried out using Annexin V-FITC/PI kit [49]. Cells $\left(2 \times 10^{5}\right)$ were collected, incubated with MTX and zein NPs, and processed according to the standard protocol [50]. Cells were further treated with Annexin V-FITC:PI and kept aside in dark for incubation, followed by addition of binding buffer prior to its analysis using a flowcytometer (BD AccuriTMC6, California, USA).

\subsubsection{Quantitative cell uptake analysis: Flow cytometry}

A flow cytometer (BD Accuri ${ }^{\mathrm{TM}} \mathrm{C6}$, California, USA) was employed to study the quantitative cellular uptake of rhodaminelabelled NPs by MCF-7 cells [51]. Cells $\left(1 * 10^{5}\right.$ cells/well) were seeded in a 6-well plate, along with complete growth medium, and were set aside for an overnight. The cells were separately incubated with free rhodamine and zein NPs-rhodamine, and kept aside for $4 \mathrm{~h}$, followed by their quantification using the flow cytometer.

\subsubsection{Caco-2 cells culture}

\subsubsection{Qualitative uptake using confocal microscopy}

Caco- 2 cells $\left(2 * 10^{5}\right.$ cells/well) were placed in a 6-well plate (BD, Falcon, New Jersey,USA), and were setaside for $24 \mathrm{~h}$ for attachment of cells over the flask surface[51]. Additionally, the cells were separately incubated with free dye and dye-loaded zein NPs for $4 \mathrm{~h}$. Cells were subsequently rinsed with the PBS ( $\mathrm{pH} 7.4)$ to wipe out the excess of medium carefully and were fixed with a solution of glutaraldehyde inethanol $(2.5 \% \mathrm{v} / \mathrm{v})$. After proper treatment, microphotographs of the nanocarriers entrapped within the cell(s) were captured with a confocal laser scanning microscope (Nikon C2+, Tokyo, Japan).

\subsection{In VivoAnimal Studies}

Animal studies were conducted as per institutional ethical committee guidelines of the Panjab University, India, after attaining the essential permission, vide number, PU/IAEC/S/15/31.

\subsubsection{In vivo animal pharmacokinetic studies}

Pharmacokinetic investigations were conductedon free MTX and zein NPs using Sprague Dawley female rats (weights: 180 to225 g), supplied by the Central Animal House Facility of the Panjab University. Prior to studies, the animals were housed in regulated conditions $\left(25 \pm 2^{\circ} \mathrm{C} / 60 \pm 5 \% \mathrm{RH}\right)$ and fasted overnight, but were allowed ad libitum access to water. Further, 3 rats were randomly placed into two different groups, and were administered with free MTX (10 mg) and equivalent amount of zein NPs, employing oral gavage.

Blood samples, measuring approximately $150 \mu \mathrm{L}$ each, were there after collected from rat retro-orbital plexus under mild anaesthesia at the scheduled time-points of $0.25,0.50,1,2,6,8,12,24$, and 48 h in HiAnticlot ${ }^{\circledR}$ vials (Himedia, Mumbai,India). Blood samples, thus collected, were centrifuged at 12,000 rpm (16,128 g) for 10 minutes, and supernatant plasma samples were estimated for MTX by an HPLC method, reported earlier by the authors [52]. The pharmacokinetic data analysis and modelling were conducted employing an add-in PK Solver ${ }^{\circledR}$ MS-Excel spread-sheet [53], adopting Wagner-Nelson technique. 
Diverse pharmacokinetic parameters like area-under-curve till 48 hours $\left(A \cup C_{48 h}\right)$, maximal plasma drug concentration $\left(C_{\text {max }}\right)$, time to attain $\mathrm{C}_{\max }\left(\mathrm{t}_{\max }\right)$, biological half-life $\left(\mathrm{t}_{1 / 2}\right)$, and mean residence time (MRT) were computed, interpreted critically, and compared to those obtained with pure drug suspension.

\subsection{In vitro/ in vivo correlation (IVIVC)}

Attempts were made to establish point-to-point linear level A IVIVC between percentages of in vitro drug released data with that of in vivo drug absorbed at the corresponding time points for MTX as well as its zein NPs, and the significance of the correlations was statistically deciphered according to the standard Fisher's ratio criterion at the appropriate degrees of freedom. The magnitudes of the total drug absorbed were calculated using Modified Wagner-Nelson technique, as MTX was found to obey one-compartment pharmacokinetic model[32].

\subsection{Stability Studies}

The lyophilized zein NPs were investigated for stability studies in order to predict their quality and integrity during different storage conditions over the course of time, employing an environmental chamber (Newtronic Lifecare, Mumbai, India). MTX being a photosensitive drug, amber-coloured glass vials were kept for a time period of 180 days at varied conditions of temperature and relative humidity $(\mathrm{RH})$, viz., $5 \pm 3^{\circ} \mathrm{C}$ and $25 \pm 2^{\circ} \mathrm{C}$ (both at $60 \pm 5 \% \mathrm{RH}$ ); and $40 \pm 2^{\circ} \mathrm{C}$ and $75 \pm 5 \% \mathrm{RH}(\mathrm{n}=3)[2,54]$. The formulations were periodically evaluated on intervals of 1, 2, 3 and 6 months for the values of their identified CQAs and compared to data obtained at the start of studies [55].

\section{Results And Discussion}

\subsection{Risk Estimation Matrix (REM)}

Figure 1 represents the Ishikawa fish-bone diagram, constructed to highlight the possible inter-relations among the selected method and material parameters and the requisite CQAs of zein NPs of MTX. Figure 2 represents the REM layout of different risk levels delineated with each variable, based upon the reported scientific literature and brain storming discussions among the team members. Only the factors linked with high or medium level of risk(s), like amount of polymer, volume of aqueous phase, time of sonication, stirring time and speed, and concentration and type of surfactant, were further selected for screening studies [38]. The remaining input variables like stirring type and method of preparation were kept at constant levels throughout the studies.

\subsection{Factor Screening Studies}

Half-normal and Pareto plots in Figure 3 vividly depict that the amount of polymer and percentage of surfactant were found to significantly influence the chosen CQAs, i.e., mean PS $(\mathrm{nm}), \mathrm{ZP}(\mathrm{mV})$ and $\mathrm{EE}(\%)$, as these remained either above Bonferroni limit and/ort-value limits. Eq 1 displays the polynomial generated for the chosen CQAs [33].

$Y=\beta_{0}+\beta_{1}+\beta_{2}+\beta_{3}+\beta_{4} \beta_{7}$...Eq. 1

where, $\beta_{0}$ presents the coefficient of intercept term, while $\beta_{1-7}$ are the corresponding linear model coefficient terms, i.e., $X_{1-7}$.

\subsection{Optimization studies and Response Surface Mapping (RSM)}

A second-order CCD was applied to carry out the optimization studies, followed by data analysis using Eq2, accounting for mainand interaction effects between the selected CMPs.

$Y=\beta_{0}+\beta_{1} X_{1}+\beta_{2} X_{2}+\beta_{3} X_{1} X_{2}+\beta_{4}+\beta_{5}$...Eq. 2

where, $\beta_{0}$ is the intercept term, $\beta_{1}$ and $\beta_{2}$ represent the coefficients of factors, and respectively, $\beta_{3}$ represents the interaction term coefficient between $X_{1}$ and $X_{2}$, and $\beta_{4}$ and $\beta_{5}$ are the corresponding quadratic coefficients of . 
Table 3 summarizes the polynomial model coefficients of varied quadratic terms and corresponding values of statistical significance of ANOVA model $(p)$ and coefficient of correlation (R).

Figure 4(a-f) portray the effect of surfactant and polymer, on the desired CQAs explored through the 3D-and 2D-response surface curves.

Figure 4(a) portrays the 3D-response surface plot between the amount of polymer and surfactant concentration for PS. On increasing the polymer concentration, a curvilinear pattern was observed, i.e.,initially a decline in the PS values, followed by a rise after the intermediate levels. A gradual decline in PS values was observed on increasing the surfactant concentration, however, this could be attributed to the tendency of surfactants to reduce the interfacial surface tension, eventually lowering the PS. The respective 2D-contour plot (Figure 4(b)) reinforces the aforesaid interpretations of the 3D-response surface.

Figure 4(c) shows the 3D-response surface between the amount of polymer and surfactant concentration for ZP. The values of ZP were observed to follow moderate curvilinear trends with rising levels of surfactant and/or polymer. The highest magnitude of ZP was seen at the highest levels of zein and the lowest levels of PF-68. Thus, higher levels of polymer and lower levels of surfactant were observed to be favourable for attainment of sufficiently high ZP values of the developed NPs. The parallel lines of 2D-contour in Figure 4(d) corroborate similar inference too.

Figure 4(e) portrays anenigmatic relationship between polymer concentration and surfactant for EE as the CQA. High EE was found to be achieved at low levels of surfactant and mid-levels of polymer. The rising ridge pattern of Figure 4(f) depicts that low levels of surfactant and middle levels of polymer could achieve higher entrapment of MTX.

Figure $\mathbf{4}(\mathrm{g})$ represents a 3D-response surface for percentage of cumulative drug release plotted against the two CMAs, viz., polymer and surfactant. With increasing polymer levels, a linear declining trend was observed upto its intermediate levels, followed by a slight increase in drug release values. However, a rise in the surfactant levels was found to increase the \% drug released, ostensibly owing to improved wetting and solubilizing potential of surfactant. Likewise, the respective2D-contour plotin Figure 4(h) also construed analogous observations.

\subsubsection{Search for Optimized Formulation and Validation Studies}

The most suitabledrug delivery formulation was selected by balancing variegated CQAs to obtain the preferred targets, i.e., minimal value of PS (which aids in drug absorption) and cumulative drug release till $48 \mathrm{~h}$ (ensures extended release profile), and maximal values of ZP (imperative for stability indication) and EE (ensures loading capacity). Following the aforesaid criteria, the optimum search was accomplished using numerical optimisation, aiming for the desirability values close to unity. Figure 5 shows the overlay plot delineating the constitution of the optimalzein NPs as per the flag, as polymer (78 mg) and surfactant (0.35\%), attaining mean PS of $159.30 \mathrm{~nm}, \mathrm{ZP}$ of $14.85 \mathrm{mV}$, EE of $50.23 \%$ and cumulative drug release of $33.90 \%$.

Table S 1 illustrates the composition of the different formulations, along with the observed and the anticipated values of CQAs and \% PPE between these. The absolute bias or \% PPE ranged between -4.55 and $4.86 \%$ with low magnitude of overall prognostic error (i.e., $0.11 \% \pm 3.06$ ), construinga high level of predictive capability of the adopted QbD methodology.

Figure $\mathbf{S} 1$ depicts the linear correlation plots, drawn between observed values of the CQAS and those predicted using RSM, and the corresponding residual curves for all the drug delivery formulations. All such correlation plots were observed to follow significant linearity, as the magnitude of R ranged between 0.9370 and 0.9787 ( $p<0.05$ to $<0.01$ ), and theanalogous residual plots were also quite controlled with narrowand indiscriminate scatter, well within the acceptable limits of $5 \%$.

\subsection{Characterization of the optimized SLNs}

\subsubsection{Mean Particle Size and Zeta Potential}

Figure 6 ( $a$ and $\mathbf{b}$ ) depict the mean PS of $159 \mathrm{~nm}$ and PDI of 0.264 , indicating monodisperse homogeneous nature of the prepared polymeric dispersion. The high magnitude of ZP, i.e., $14.85 \mathrm{mV}$, construed good stability of the developed systemand 


\subsubsection{Electron Microscopic Studies}

Figure 7 ( $\mathbf{a}$ and $\mathbf{b}$ )show the TEM and FESEM microphotographs of the optimised formulation, respectively, construing segregated and round-shaped particles with smooth surface and size under $200 \mathrm{~nm}$. Such interpretation of size ranges was found to be in agreement with those obtained earlier during particle size measurement (Section 4.4.1).

\subsubsection{Drug Release Kinetics Modelling}

Studies on cumulative MTX release profiles on zein NPs revealed a sustained release pattern of MTX from the polymeric NPs, when compared to naïve drug suspension (Figure 8). It is quite evident that more than half fraction of pure MTX got released within the first 30 minutes, while it took over $8 \mathrm{~h}$ to release the same extent of drug from the optimized NPs. Table 4 enlists the outcomes of fitting of release data into various mathematical models. Statistical significance of regression (i.e., $\mathrm{F}$ ratio) construed Korsmeyer-Peppas mathematical model $(p<0.001)$ as the most suitable strategy to unravel the mechanism of MTX release kinetics [57]. The values of diffusional release exponent $(n)$ indicated Fickian release mechanism of MTX ( $n=0.181)$, and non-Fickian or anomalous release behaviour from the optimized NPs $(n=0.5681)$ [55]. Weibull model fitting on drug release data revealed the values of dissolution curve shape parameter ( $\beta$ )to be ranging between 0.444 and 0.723 (i.e., $<1$ ) for MTX as well zein NPs, thus representing an initial steep slope, followed by an exponential-type of curvature. On the other hand, the magnitude of Weibull time-scale parameter (a) for zein NPs (i.e., 4.854) were found to be superior to those of pure drug (i.e., 0.876), indicating discrete drug release extension from the NPs [58].

The values of location parameter $(\mathrm{Ti})$ obtained with both pure MTX as well as with the optimized NPs indicated that the onset of dissolution process was quite instantaneous [36]. Attempts to fit the data in Baker-Lonsdale model for NPs too indicated high degree of fitness $(R=0.9840 ; p<0.001)$ construing regulated drug release characteristics from the spherically shaped NPs [59]. On the other hand, pure drug data failed to yield statistically significant results.

\subsection{Cell culture study}

\subsubsection{MTT assay}

Figure 9 depicts concentration-dependent cell cytotoxicity of MCF-7 cells on interacting with plain MTX suspension and zein NPs, evidently indicating much higher cytotoxicity of the latter vis-à-vis the former. The $\mathrm{IC}_{50}$ values were found to be approximately 37.78 and $12.77 \mu \mathrm{g} / \mathrm{mL}$ for pure drug and optimized NPs, respectively, thus justifying almost 3-folds improvement in cytotoxicity and efficacy of the latter. The enhanced cytotoxicity of the optimized formulation could be attributed to its cationic nature and minuscule particle size, which may enhance cellular internalization across the MCF-7 cells, followed by subsequent release of MTX from zein NPs [60].

\subsubsection{Apoptosis assay}

Figure 10 shows the quantitative estimation of programmed cell death caused by MTX and its zein NPs in the stoichiometrically equivalent concentraions (i.e., $12.77 \mu \mathrm{g} / \mathrm{mL}$ ). Almost $12.9 \%$ of cells were observed to be in the initial apoptotic phase on treatment with zein NPs, to that of 2.1 and $0.5 \%$ cells for MTX pure and reference control of untreated cells, respectively. Nevertheless, the count of cells in the late apoptotic phase increased to $0.9 \%$ (reference control) and 1.1\% (MTX) to $3.4 \%$ (zein NPs), on treatment. Superior apoptosis was observed with zein NPs, which can be ascribed to the enhanced permeation of the carrier system due to their positive charge and the subsequent internalization across the cell membrane due to its minuscule size [56].

\subsubsection{Quantitative cellular uptake}


Figure 11 (a-d) illustrates the cellular uptake of $\mathrm{C}_{6}$ by MCF-7 cells, when exposed to free MTX and its optimized zein NPs. The quantum of percent $\mathrm{C}_{6}$ values, measured using FACS analysiswas found to be approximately 141 -folds with the latter vis-à-vis the control (i.e., untreated cells). Improved fluorescent intensity of $\mathrm{C}_{6}$ was found with zein NPs, which can again be attributed to the integrated effect of nanometric size and cationic nature of the polymer [61].

\subsubsection{Cellular uptake studies}

Figure 12 (a-d) depicts the qualitative cellular uptake of $\mathrm{C}_{6}$-loaded zein NPs ( $\mathrm{C}_{6}$-zein NPs) and pure $\mathrm{C}_{6}$ in Caco-2 cell lines. Negligible fluorescent characteristics were noticed, as free $\mathrm{C}_{6}$ was not freely internalised by the cell lines [62]. Besides, high fluorescent intensity was noticed with $_{6}$-zein NPs (Figure 12 (d)), assignable again the positive charge and diminutive size of the NPs thus facilitating their endocytosis across the cellular membrane [63, 64].

\subsection{In vivopharmacokinetic studies}

Figure 13 displays 48-h plasma drug level (mean \pm SD) profiles of pure MTX suspension and zein NPs. The respective inset represents percentage alteration in the values of pharmacokinetic metrics following intake of MTX NPs compared pure MTX. The results showed quite enhanced biopharmaceutical attributes of zein NPs vis-à-vis naïve drug, with with nearly 2.15-folds improvement in $\mathrm{AUC}_{48 \mathrm{~h}}(\mathrm{p}<0.001), 1.30$-folds in $\mathrm{C}_{\max }(\mathrm{p}<0.05), 3.67$-folds in $\mathrm{T}_{\max }(\mathrm{p}<0.001), 1.38$-folds in $\mathrm{T}_{1 / 2}(\mathrm{p}<0.01)$, and 1.64folds in MRT $(p<0.01)$. Also, the values of percent coefficient of variation $(\% \mathrm{CV})$ noticed with zein NPs (i.e., ranging between 5.8 and $59.8 \%$; mean $\mathrm{CV}: 23.5 \%$ ) indicated superior consistency in plasma level data over that of pure MTX suspension (i.e., ranging between $12.3 \%$ and $81.8 \%$, mean CV: $41.9 \%$ ). Significant improvement in various absorption parameters and consistency in plasma level data were noticeable with NPs, than pure MTX. Overall, distinctive improvement in the magnitude of biopharmaceutical attributes demonstrates significant augmentation in the extent of biovailbility, as well as extension and consistency in of plasma MTX levels, on its incorporation in the zein NPs.

\subsection{IVIVCstudies}

Figure 14 portrays the linear curves for level A IVIVC for MTX and its zein NPs. High values of coefficient of correlation (R) were observed for MTX zein NPs (i.e., $R=0.9716, p<0.01$ ) as well as for pure MTX (i.e., $R=0.9426, p<0.05$ ) with linearmodel fitted between cumulative percentages of dissolved drug in vitro with those of absorbed drug in vivo [32,36]. Embarking upon of statistically valid IVIVC's, accordingly, corroborate the robustness of in vitro drug dissolution evaluation methodology, including that of drug release medium composition, dissolution apparatus type, sampling schedule and stirring conditions, as quite prognostic and simulative of in vivo biopharmaceutical performance of MTX. Successful establishment of such IVIVC's have already been reported in the literature for various BCS class II and IV drugs, and their consequent drug delivery systems [32, 36, 47, 65].

\subsection{Stability studies}

The results of stability studies are summarized in Table S2. Relatively mild to notable rise in mean size of particles may be ascribed to the reduced viscosity of the delivery system, during different storage conditions. This eventually led to the high kinetic energy and number of collisions throughout the particles ultimately resulting in aggregation of NPs at room temperature (Shah et al., 2014). Besides, modest decline was observed in the magnitude of zeta potential, cumulative drug release and efficiency of entrapment, during storage at $25^{\circ} \mathrm{C}$ and $40{ }^{\circ} \mathrm{C}$, which may majorly be accountable to the possible denaturation of the proteinaceous structure of zein, resulting in high drug leakage from the NPs [66]. The NPs, stored under the refrigerated conditions, on the other hand, were found to be stable during storage period of three months, without any significant change in the values of CQAs [67].

The NPs, stored under the refrigerated conditions, on the other hand, were found to be stable during storage period of three months, without any significant change in the values of CQAs.

\section{Conclusion}


The current studies were planned to explore the plausible enhancement and extension in biopharmaceutical performance of MTX, when formulated as zein NPs. Implementation of QbD strategy aided in holistic know-how of the nanoparticulate formulation development while achievingthe QTPP requirements. NPs demonstrated significantly higher cytotoxicity and improved uptake potential than pure MTX during in vitro evaluation, ostensibly ascribable to their nanometric size and cationic surface charge. Notable extension in pharmacokinetic profile, augmentation in the extent of bioavailability, and diminution in data variability were observed with zein NPs. Stability studies ratified the robustness of zein NPs under refrigerated conditions when stored for three months. Concisely, the findings of the current research work substantiate superior formulation robustness, and extended, regulated and consistent biopharmaceutical performance of MTX NPs, resulting in its high therapeutic potential in breast tumour(s). Successful outcomes observed with polymeric NPs, employing zein as a natural, biodegradable and economical polymer, can be rationally explored and extrapolated for other biopharmaceutucally enigmatic drug molecules too.

\section{Declarations}

\section{ETHICAL STATEMENT:}

- Ethics approval and consent to participate: Animal studies were conducted as per institutional ethical committee guidelines of the Panjab University, India, after attaining the essential permission, vide number, PU/IAEC/S/15/31

- Consent for publication: Yes

- Availability of data and materials: On request

- Competing interests: None

- Funding: University Grants Commission (UGC, IN)

- Authors' contributions:

Atul Jain: Data curation; Formal analysis; Funding acquisition; Investigation; Methodology

Teenu Sharma: Validation; Writing - original draft

Rajendra Kumar: Cell line studies

Sumant Saini: Editing

Jasleen Kaur: Analysis and editing

OP Katare: Supervision

Bhupinder Singh: Conceptualization; Visualization; Project administration; Resources; Software; Supervision; Writing - review \& editing

- Acknowledgements: Authors put to record their thankfulness to the University Grants Commission, India, for providing requisite fiscal grants for the research work under the aegis of Centre of Excellence in NanoBiomedicine. The corresponding author (B.S.) gratefully acknowledgesStat-Ease Inc., Minneapolis, USA, for gifting premium and annual licenses of Design Expert $^{\circledR}$ software 11.0 version to him and his team,respectively, as an Award of Distinction for his stellarcontribution in QbDsteered research work for systematically developing novel drug delivery systems as well as validated analytical methods.

\section{References}

1. Khurana RK, Jain A, Sharma T, Singh B, Kesharwani P. Administration of antioxidants in cancer: debate of the decade. Drug Disco Today. 2018;23(4):763-70.

2. WHO. Stability testing of active pharmaceutical ingredients and finished pharmaceutical products. 2018 [cited 202121 July]; Available from:

https://www.ich.org/fileadmin/Public_Web_Site/ICH_Products/Guidelines/Quality/Q1F/Stability_Guideline_WHO_2018.pdf.

Page 10/23 
3. Madan J, Gundala SR, Kasetti Y, Bharatam PV, Aneja R, Katyal A, Jain UK. Enhanced noscapine delivery using estrogenreceptor-targeted nanoparticles for breast cancer therapy. Anti-cancer drugs. 2014;25(6):704-16.

4. Jain A, Jain A, Garg NK, Tyagi RK, Singh B, Katare OP, Webster TJ, et al. Surface engineered polymeric nanocarriers mediate the delivery of transferrin-methotrexate conjugates for an improved understanding of brain cancer. Acta Biomater. 2015;24:140-51.

5. Papich MG, Martinez MN. Applying biopharmaceutical classification system (BCS) criteria to predict oral absorption of drugs in dogs: Challenges and pitfalls. AAPS PharmSciTech. 2015;17(4):948-64.

6. Murakami T, Mori N. Involvement of multiple transporters-mediated transports in mizoribine and methotrexate pharmacokinetics Pharmaceuticals, 2012. 5:802-836.

7. Hoekstra M, Haagsma C, Neef C, Proost J, Knuif A, van de Laar M. Bioavailability of higher dose methotrexate comparing oral and subcutaneous administration in patients with rheumatoid arthritis. J Rheumatol. 2004;31(4):645-8.

8. Bello AE, Perkins EL, Jay R, Efthimiou P. Recommendations for optimizing methotrexate treatment for patients with rheumatoid arthritis. Open Access Rheumatol. 2017;9:67-79.

9. Teresi ME, Crom WR, Choi KE, Mirro J, Evans WE. Methotrexate bioavailability after oral and intramuscular administration in children. J Pediatr. 1987;110(5):788-92.

10. Campbell MA, Perrier DG, Dorr RT, Alberts DS, Finley PR. Methotrexate: bioavailability and pharmacokinetics. Cancer Treat Rep. 1985;69(7-8):833-8.

11. Abolmaali S, Tamaddon AM, Dinarvand R. A review of therapeutic challenges and achievements of methotrexate delivery systems for treatment of cancer and rheumatoid arthritis. Cancer Chemother Pharmacol. 2013;71(5):1115-30.

12. Przekop PR Jr, Tulgan H, Przekop AA, Glantz M. Adverse drug reaction to methotrexate: pharmacogenetic origin. J Am Osteopath Assoc. 2006;106(12):706-7.

13. Singh UV, Udupa N. Methotrexate loaded chitosan and chitin microspheres-in vitro characterization and pharmacokinetics in mice bearing Ehrlich ascites carcinoma. J Microencapsul. 1998;15(5):581-94.

14. Chavanpatil MD, Khdair A, Patil Y, Handa H, Mao G, Panyam J. Polymer-surfactant nanoparticles for sustained release of water-soluble drugs. J Pharm Sci. 2007;96(12):3379-89.

15. Stebbins ND, Faig JJ, Yu W, Guliyev R, Uhrich KE. Polyactives: controlled and sustained bioactive release via hydrolytic degradation. Biomater Sci. 2015;3(8):1171-87.

16. Kuznetsova NR, Sevrin C, Lespineux D, Bovin NV, Vodovozova EL, Mészáros T, Szebeni J, et al. Hemocompatibility of liposomes loaded with lipophilic prodrugs of methotrexate and melphalan in the lipid bilayer. J Control Release. 2012;160(2):394-400.

17. Al-Nemrawi NK, Marques J, Tavares CJ, Oweis RJ, Al-Fandi MG. Synthesis and characterization of photocatalytic polyurethane and poly (methyl methacrylate) microcapsules for the controlled release of methotrexate. Drug Dev Ind Pharm. 2018;44(12):2083-8.

18. Gharebaghi F, Dalali N, Ahmadi E, Danafar H. Preparation of wormlike polymeric nanoparticles coated with silica for delivery of methotrexate and evaluation of anticancer activity against MCF7 cells. J Biomater Appl. 2017;31(9):1305-16.

19. Ferreira M, Chaves LL, Lima SAC, Reis S. Optimization of nanostructured lipid carriers loaded with methotrexate: a tool for inflammatory and cancer therapy. Int J Pharm. 2015;492(1-2):65-72.

20. Battaglia L, Muntoni E, Chirio D, Peira E, Annovazzi L, Schiffer D, Mellai M, et al. Solid lipid nanoparticles by coacervation loaded with a methotrexate prodrug: Preliminary study for glioma treatment. Nanomedicine. 2017;12(6):639-56.

21. Beg S, Jain S, Kushwah V, Bhatti GK, Sandhu PS, Katare OP, Singh B. Novel surface-engineered solid lipid nanoparticles of rosuvastatin calcium for low-density lipoprotein-receptor targeting: a quality by design-driven perspective. Nanomedicine (Lond). 2017;12(4):333-56.

22. Nabi-Meibodi M, Vatanara A, Najafabadi AR, Rouini MR, Ramezani V, Gilani K, Etemadzadeh SMH, et al. The effective encapsulation of a hydrophobic lipid-insoluble drug in solid lipid nanoparticles using a modified double emulsion solvent evaporation method. Colloids Surf B. 2013;112:408-14.

Page $11 / 23$ 
23. Lai LF, Guo HX. Preparation of new 5-fluorouracil-loaded zein nanoparticles for liver targeting. Int J Pharm. 2011;404(12):317-23.

24. Paliwal R, Palakurthi S. Zein in controlled drug delivery and tissue engineering. J of Control Release. 2014;189:108-22.

25. Fu J, Wang H, Zhou Y, Wang J. Antibacterial activity of ciprofloxacin-loaded zein microsphere films. Mater Sci Eng C. 2009;29(4):1161-6.

26. Lai LF, Guo HX. Preparation of new 5-fluorouracil-loaded zein nanoparticles for liver targeting. Int J Pharm. 2011;404(12):317-23.

27. Zhong Q, Jin M. Nanoscalar structures of spray-dried zein microcapsules and in vitro release kinetics of the encapsulated lysozyme as affected by formulations. J Agric Food Chem. 2009;57(9):3886-94.

28. Lee S, Alwahab NS, Moazzam ZM. Zein-based oral drug delivery system targeting activated macrophages. Int J Pharm. 2013;454(1):388-93.

29. Parris N, Cooke PH, Hicks KB. Encapsulation of essential oils in zein nanospherical particles. J Agric Food Chem. 2005;53(12):4788-92.

30. Patel A, Hu Y, Tiwari JK, Velikov KP. Synthesis and characterisation of zein-curcumin colloidal particles. Soft Matter. 2010;6(24):6192-9.

31. Zou T, Gu L. TPGS emulsified zein nanoparticles enhanced oral bioavailability of daidzin: in vitro characteristics and in vivo performance. Mol Pharm. 2013;10(5):2062-70.

32. Sharma T, Katare OP, Jain A, Jain S, Chaudhari D, Borges B, Singh B. QbD-Steered Development of Biotin-Conjugated Nanostructured Lipid Carriers for Oral Delivery of Chrysin: Role of Surface Modification for Improving Biopharmaceutical Performance. Colloids Surfaces B: Biointerfaces. 2021;197:111429.

33. Singh B, Kumar R, Ahuja N. Optimizing drug delivery systems using systematic" design of experiments." Part l: fundamental aspects. Crit Rev Ther Drug Carrier Syst. 2005;22(1):27-105.

34. Fröhlich E. The role of surface charge in cellular uptake and cytotoxicity of medical nanoparticles. Int J Nanomedicine. 2012;7:5577.

35. Singh B, Bhatowa R, Tripathi CB, Kapil R. Developing micro-/nanoparticulate drug delivery systems using "design of experiments". International journal of pharmaceutical investigation. 2011;1(2):75.

36. Sharma T, Jain A, Kaur R, Saini S, Katare OP, Singh B. Supersaturated LFCS type III self-emulsifying delivery systems of sorafenib tosylate with improved biopharmaceutical performance: QbD-enabled development and evaluation. Drug Deliv Transl Res. 2020;10:839-61.

37. Singh B, Kaisar R, Beg S, Developing “ Optimized "Drug Products Employing "Designed " Experiments, in Chem. Ind. Digest 2013, Blockdale Media LLP: India. p. 70-76.

38. Singh B, Saini S, Lohan S, Beg S. Systematic development of nanocarriers employing quality by design paradigms. In: Mishra $V$ et al, editors. Nanotechnology-Based Approaches for Targeting and Delivery of Drugs and Genes. Academic Press; 2017. pp. 110-48.

39. Singh B, Sharma T, Saini S, Kaur R, Jain A, Raza K, Beg S. Systematic Development of Drug Nanocargos Using Formulation by Design (FbD): An Updated Overview. Crit Rev Ther Drug Carrier Syst. 2020;37(3):229-69.

40. Sandhu PS, Beg S, Katare OP, Singh B. QbD-driven development and validation of a HPLC method for estimation of tamoxifen citrate with improved performance. J Chromatogr Sci. 2016;54(8):1373-84.

41. Farsani PA, Mahjub R, Mohammadi M, Oliaei SS, Mahboobian MM. Development of Perphenazine-Loaded Solid Lipid Nanoparticles: Statistical Optimization and Cytotoxicity Studies. BioMed Research International, 2021. 2021.

42. Zhang H, van Os WL, Tian X, Zu G, Ribovski L, Bron R, Bussmann J, et al. Development of curcumin-loaded zein nanoparticles for transport across the blood-brain barrier and inhibition of glioblastoma cell growth. Biomater. Sci., 2021:1-12.

43. Soppimath KS, Aminabhavi TM, Kulkarni AR, Rudzinski WE. Biodegradable polymeric nanoparticles as drug delivery devices. J Control Release. 2001;70(1-2):1-20. 
44. Zara RF, Bittencourt PRS, Tiuman TS, Galan V, de Souza FP, Ávila ÉRK. Application of zein and chitosan in the development of a colon-specific delivery system. J App Pharm Sci. 2021;11(07):089-97.

45. ATCC. MCF7 (ATCC® HTB-22 ${ }^{\text {TM }}$ ). 2019 [cited 2021 July 25]; Available from: https://www.atcc.org/products/all/HTB22.aspx.

46. Nobili S, Mannini A, Parenti A, Raggi C, Lapucci A, Chiorino G, Paccosi S, et al. Establishment and characterization of a new spontaneously immortalized ER-/PR-/HER2 + human breast cancer cell line. DHSF-BR16 Scientific reports. 2021;11(1):115.

47. Jain A, Kaur R, Beg S, Kushwah V, Jain S, Singh B. Novel cationic supersaturable nanomicellar systems of raloxifene hydrochloride with enhanced biopharmaceutical attributes. Drug Deliv Transl Res. 2018a;8(3):670-92.

48. Jain A, Sharma T, Sharma G, Khurana RK, Katare OP, Singh B. QbD driven analytical method development and validation for raloxifene hydrochloride in pure drug and solid oral dosage form. Anal Chem Lett, 2019:1-16.

49. Al-Zharani M, Nasr FA, Alqahtani AS, Cordero MAW, Alotaibi AA, Bepari A, Alarifi S, et al. In Vitro Cytotoxic Evaluation and Apoptotic Effects of Datura innoxia Grown in Saudi Arabia and Phytochemical Analysis. Applied Sci. 2021;11(6):2864.

50. Riccardi C, Nicoletti I. Analysis of apoptosis by propidium iodide staining and flow cytometry. Nat Protoc. 2006;1(3):145861.

51. Lyon PC, Suomi V, Jakeman P, Campo L, Coussios C, Carlisle R. Quantifying cell death induced by doxorubicin, hyperthermia or HIFU ablation with flow cytometry. Scientific reports. 2021;11(1):1-19.

52. Jain A, Beg S, Saini S, Sharma T, Katare OP, Singh B. Application of chemometric approach for QbD-enabled development and validation of an RP-HPLC method for estimation of methotrexate. J Liq Chromat Rel Technol. 2019;42(15-16):502-12.

53. Zhang Y, Huo M, Zhou J, Xie S, PKSolver. An add-in program for pharmacokinetic and pharmacodynamic data analysis in microsoft excel. Comput Methods Programs Biomed. 2010;99(3):306-14.

54. Kim DS, Cho JH, Park JH, Kim JS, Song ES, Kwon J, Giri BR, et al. Self-microemulsifying drug delivery system (SMEDDS) for improved oral delivery and photostability of methotrexate. Int J Nanomedicine. 2019;14:4949.

55. Makoni PA, Wa KK, Walker RB. Short term stability testing of efavirenz-loaded solid lipid nanoparticle (SLN) and nanostructured lipid carrier (NLC) dispersions. Pharmaceutics. 2019;11(8):397-417.

56. Mahalakshmi L, Leena MM, Moses JA, Anandharamakrishnan C. Micro-and nano-encapsulation of $\beta$-carotene in zein protein: size-dependent release and absorption behavior. Food Funct. 2020;11(2):1647-60.

57. Singh B, Singh S. A comprehensive computer program for the study of drug release kinetics from compressed matrices. Indian journal of pharmaceutical sciences. 1998;60(6):358.

58. Jahromi LP, Ghazali M, Ashrafi H, Azadi A. A comparison of models for the analysis of the kinetics of drug release from PLGA-based nanoparticles. Heliyon. 2020;6(2):e03451.

59. Kayes SY, Islam MM, Hamidur RM, Nazmus S. A comparative study on Naproxen Sodium tablets formulating with different super disintegrants. GSC Biol Pharm Sci. 2019;9(3):076-84.

60. Jain A, Sharma G, Kushwah V, Ghoshal G, Jain A, Singh B, Shivhare US, et al. Beta carotene-loaded zein nanoparticles to improve the biopharmaceutical attributes and to abolish the toxicity of methotrexate: a preclinical study for breast cancer. Artif. Cells Nanomed, Biotechnol., 2018b. 46(sup1):pp. 402-12.

61. Wang X, Fan, MJRa. Interaction behaviors and structural characteristics of zein/NaTC nanoparticles. 2019. 9(10):57485755.

62. Win YK, Feng SS. Effects of particle size and surface coating on cellular uptake of polymeric nanoparticles for oral delivery of anticancer drugs. Biomaterials. 2005;26:2713-22.

63. Shi S, Han L, Deng L, Zhang Y, Shen H, Gong T, Zhang Z, et al. Dual drugs (microRNA-34a and paclitaxel)-loaded functional solid lipid nanoparticles for synergistic cancer cell suppression. J Control Release. 2014;194:228-37.

64. Elliott NT, Yuan F. A microfluidic system for investigation of extravascular transport and cellular uptake of drugs in tumors. BiotechnolBioeng. 2012;109(5):1326-35. 
65. Singh B, Garg B, Chaturvedi SC, Arora S, Mandsaurwale R, Kapil R, Singh B. Formulation development of gastroretentive tablets of lamivudine using the floating-bioadhesive potential of optimized polymer blends. J Pharm Pharmacol.

2012;64(5):654-69.

66. Shah R, Eldridge D, Palombo E, Harding I. Optimisation and Stability Assessment of Solid Lipid Nanoparticles using Particle Size and Zeta Potential. J Phys Sci. 2014;25(1):59-75.

67. Lai LF, Guo H. Preparation of new 5-fluorouracil-loaded zein nanoparticles for liver targeting. Int J Pharm. 2011;404(12):317-23.

\section{Tables}

Table 1: Seven-variables eight-run Taguchi orthogonal array for screening of different material and process parameters during formulation of polymer nanoparticles of methotrexate

\begin{tabular}{|c|c|c|c|c|c|c|c|c|}
\hline Run & $\begin{array}{l}\text { Amount of } \\
\text { Polymer }\end{array}$ & $\begin{array}{l}\text { Type of } \\
\text { Surfactant }\end{array}$ & $\begin{array}{l}\text { Stirring } \\
\text { Speed }\end{array}$ & $\begin{array}{l}\text { Conc. of } \\
\text { Surfactant (\%) }\end{array}$ & $\begin{array}{l}\text { Stirring } \\
\text { Time }\end{array}$ & \multicolumn{2}{|c|}{$\begin{array}{l}\text { Volume of Aqueous } \\
\text { Phase }\end{array}$} & $\begin{array}{l}\text { Sonication } \\
\text { Time }\end{array}$ \\
\hline 1 & +1 & -1 & -1 & +1 & -1 & \multicolumn{2}{|l|}{-1} & +1 \\
\hline 2 & -1 & -1 & +1 & +1 & +1 & \multicolumn{2}{|l|}{-1} & -1 \\
\hline 3 & -1 & +1 & -1 & -1 & -1 & \multicolumn{2}{|l|}{-1} & -1 \\
\hline 4 & -1 & -1 & +1 & -1 & -1 & \multicolumn{2}{|c|}{+1} & +1 \\
\hline 5 & +1 & -1 & -1 & -1 & +1 & \multicolumn{2}{|c|}{+1} & -1 \\
\hline 6 & -1 & +1 & -1 & +1 & +1 & \multicolumn{2}{|c|}{+1} & +1 \\
\hline 7 & +1 & +1 & +1 & -1 & +1 & \multicolumn{2}{|l|}{-1} & +1 \\
\hline 8 & +1 & +1 & +1 & +1 & -1 & \multicolumn{2}{|c|}{+1} & -1 \\
\hline & & & & & \multicolumn{4}{|c|}{ Level of Factor studies } \\
\hline \multicolumn{3}{|c|}{ Selected Parameter } & & & \multicolumn{2}{|l|}{ Low $(-1)$} & \multicolumn{2}{|l|}{ High (+1) } \\
\hline \multicolumn{3}{|c|}{ Amount of Polymer (mg) } & & & \multicolumn{2}{|l|}{50} & \multicolumn{2}{|l|}{100} \\
\hline \multicolumn{3}{|c|}{ Type of Surfactant (T/P) } & & & \multicolumn{2}{|c|}{ Tween $80(\mathrm{~T})$} & \multicolumn{2}{|c|}{ Pluronic F-68 (P) } \\
\hline \multicolumn{3}{|c|}{ Stirring speed (rpm) } & & & \multicolumn{2}{|l|}{500} & \multicolumn{2}{|l|}{1000} \\
\hline \multicolumn{3}{|c|}{ Surfactant (\%) } & & & \multicolumn{2}{|l|}{0.25} & \multicolumn{2}{|l|}{0.5} \\
\hline \multicolumn{3}{|c|}{ Stirring time (min) } & & & \multicolumn{2}{|l|}{120} & \multicolumn{2}{|l|}{180} \\
\hline \multicolumn{3}{|c|}{ Volume of aqueous phase $(\mathrm{mL})$} & & & \multicolumn{2}{|l|}{20} & \multicolumn{2}{|l|}{40} \\
\hline \multicolumn{3}{|c|}{ Sonication time (sec) } & & & \multicolumn{2}{|l|}{30} & \multicolumn{2}{|l|}{60} \\
\hline
\end{tabular}

Table 2: Design matrix as per the CCD for the optimization of polymeric nanoparticles of MTX 


\begin{tabular}{|c|c|c|c|c|}
\hline \multirow[t]{2}{*}{ Run } & \multicolumn{4}{|c|}{ Coded factor levels } \\
\hline & \multicolumn{2}{|c|}{ Factor $1\left(X_{1}\right)$} & \multicolumn{2}{|c|}{ Factor $2\left(X_{2}\right)$} \\
\hline 1 & \multicolumn{2}{|l|}{+1} & \multicolumn{2}{|l|}{0} \\
\hline 2 & \multicolumn{2}{|l|}{-1} & \multicolumn{2}{|l|}{-1} \\
\hline 3 & \multicolumn{2}{|l|}{-1} & \multicolumn{2}{|l|}{+1} \\
\hline 4 & \multicolumn{2}{|l|}{+1} & \multicolumn{2}{|l|}{-1} \\
\hline 5 & \multicolumn{2}{|l|}{+1} & \multicolumn{2}{|l|}{+1} \\
\hline 6 & \multicolumn{2}{|l|}{0} & \multicolumn{2}{|l|}{0} \\
\hline 7 & \multicolumn{2}{|l|}{0} & \multicolumn{2}{|l|}{0} \\
\hline 8 & \multicolumn{2}{|l|}{0} & \multicolumn{2}{|l|}{-1} \\
\hline 9 & \multicolumn{2}{|l|}{0} & \multicolumn{2}{|l|}{0} \\
\hline 10 & \multicolumn{2}{|l|}{0} & \multicolumn{2}{|l|}{+1} \\
\hline 11 & \multicolumn{2}{|l|}{0} & \multicolumn{2}{|l|}{0} \\
\hline 12 & \multicolumn{2}{|l|}{0} & \multicolumn{2}{|l|}{0} \\
\hline 13 & \multicolumn{2}{|l|}{-1} & \multicolumn{2}{|l|}{0} \\
\hline \multirow[t]{3}{*}{ Selected parameters } & \multicolumn{4}{|c|}{ Decoded factor levels } \\
\hline & Low & Inter & ediate & High \\
\hline & $(-1)$ & $(0)$ & & $(+1)$ \\
\hline Amount of polymer (mg) & 50 & 75 & & 100 \\
\hline Surfactant (\%) & 0.20 & 0.35 & & 0.50 \\
\hline
\end{tabular}

Table 3: Coefficients of polynomial equation as per the second-order modified quadratic model for each of the critical quality attributes

\begin{tabular}{|lllll|}
\hline Coefficient code & \multicolumn{4}{l}{ Polynomial coefficients for critical analytical attributes } \\
\cline { 2 - 5 } & Particle Size & Zeta Potential & EE (\%) & Release (\%) \\
\hline $\boldsymbol{\beta}_{0}$ & +153.73 & +14.58 & +49.71 & +33.72 \\
\hline $\boldsymbol{\beta}_{1}$ & +44.32 & +2.62 & +5.71 & -0.67 \\
$\boldsymbol{\beta}_{2}$ & -16.18 & -1.45 & -1.78 & +5.90 \\
$\boldsymbol{\beta}_{3}$ & -17.95 & -0.4000 & -6.02 & +1.14 \\
$\boldsymbol{\beta}_{4}$ & +51.65 & +0.5224 & -6.33 & +5.07 \\
\hline $\boldsymbol{\beta}_{5}$ & +8.75 & +1.12 & +1.98 & -5.35 \\
\hline P-value & $<0.0001$ & $<0.001$ & $<0.010$ & $<0.005$ \\
\hline R & 0.9794 & 0.9485 & 0.9032 & 0.9109 \\
\hline
\end{tabular}

Table 4: Results of fitting various mathematical modelling approaches to drug release kinetic data of MTX and its optimized zein nanoparticulate formulation 


\begin{tabular}{|c|c|c|c|}
\hline \multicolumn{4}{|l|}{ Pure MTX } \\
\hline Mathematical Model & Correlation coefficient & Model coefficient & Statistical significance \\
\hline First-order & 0.8485 & 0.086 & $<0.05$ \\
\hline Zero-order & 0.7107 & 4.9477 & $<0.05$ \\
\hline Higuchi & 0.8562 & 21.771 & $<0.05$ \\
\hline \multirow[t]{3}{*}{ Weibull } & 0.9320 & $a=0.876$ & $<0.05$ \\
\hline & & $\beta=0.444$ & \\
\hline & & $\mathrm{Ti}=0.00$ & \\
\hline Hixson-Crowell Cube Root & 0.8117 & 0.1832 & $<0.05$ \\
\hline Baker-Lonsdale & 0.8450 & 0.042 & $<0.05$ \\
\hline Korsmeyer-Peppas & 0.9560 & 0.1818 & $<0.001$ \\
\hline \multicolumn{4}{|l|}{ Zein-NPs of MTX } \\
\hline Mathematical Model & Correlation coefficient & Model coefficient & Statistical significance \\
\hline First-order & 0.9145 & 0.0335 & $<0.05$ \\
\hline Zero-order & 0.8793 & 3.5539 & NS \\
\hline Higuchi & 0.8793 & 3.5539 & NS \\
\hline \multirow[t]{3}{*}{ Weibull } & 0.9579 & $a=4.854$ & $<0.05$ \\
\hline & & $\beta=0.723$ & \\
\hline & & $\mathrm{Ti}=0.00$ & \\
\hline Hixson-Crowell Cube Root & 0.9242 & 0.0903 & $<0.05$ \\
\hline Baker-Lonsdale & 0.9840 & 0.010 & $<0.001$ \\
\hline Korsmeyer-Peppas & 0.9823 & 0.5681 & $<0.001$ \\
\hline
\end{tabular}

${ }^{\#} p$ computed on the basis of significance of regression; NS: not significant at $5 \%$ level (i.e., $p>0.05$ )

\section{Figures}

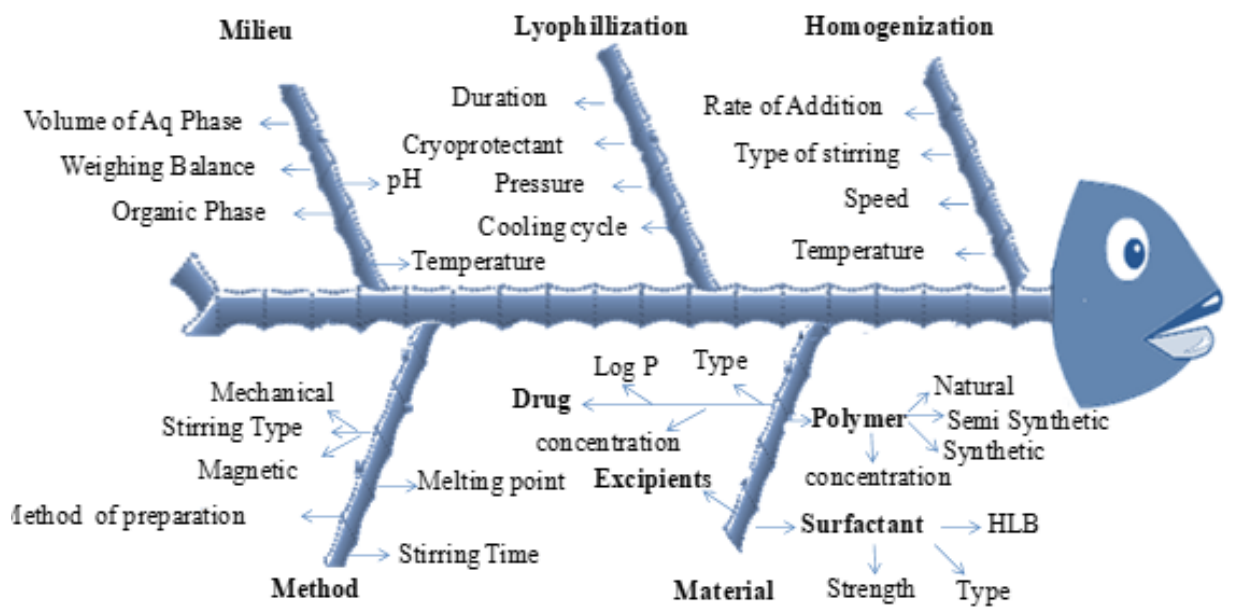


Figure 1

An Ishikawa-fish bone diagram depicting various factors affecting the formulation development process of zein nanoparticles

\begin{tabular}{|c|c|c|c|c|c|c|c|c|c|}
\hline CAAs & $\begin{array}{c}\text { Amount } \\
\text { of } \\
\text { polymer }\end{array}$ & $\begin{array}{c}\text { Type of } \\
\text { surfactant }\end{array}$ & $\begin{array}{c}\text { Surftant } \\
(\%)\end{array}$ & $\begin{array}{c}\text { Sonication } \\
\text { time }\end{array}$ & $\begin{array}{c}\text { Stirring } \\
\text { type }\end{array}$ & $\begin{array}{c}\text { Stirring } \\
\text { speed }\end{array}$ & $\begin{array}{c}\text { Stirring } \\
\text { time }\end{array}$ & $\begin{array}{c}\text { Volume } \\
\text { of } \\
\text { aqueous } \\
\text { phase }\end{array}$ & $\begin{array}{c}\text { Method } \\
\text { of } \\
\text { preparation }\end{array}$ \\
\hline $\begin{array}{c}\text { Particle } \\
\text { size }\end{array}$ & High & Medium & High & High & Low & High & High & Medium & Medium \\
\hline $\begin{array}{c}\text { Zeta } \\
\text { potential }\end{array}$ & High & Low & Medium & Low & Low & Medium & Medium & Medium & Low \\
\hline EE (\%) & High & Medium & HIgh & Medium & Low & High & Medium & Medium & Low \\
\hline
\end{tabular}

\section{Figure 2}

A risk estimation matrix (REM) for evaluating risk levels of various input parameters for zein nanoparticles 

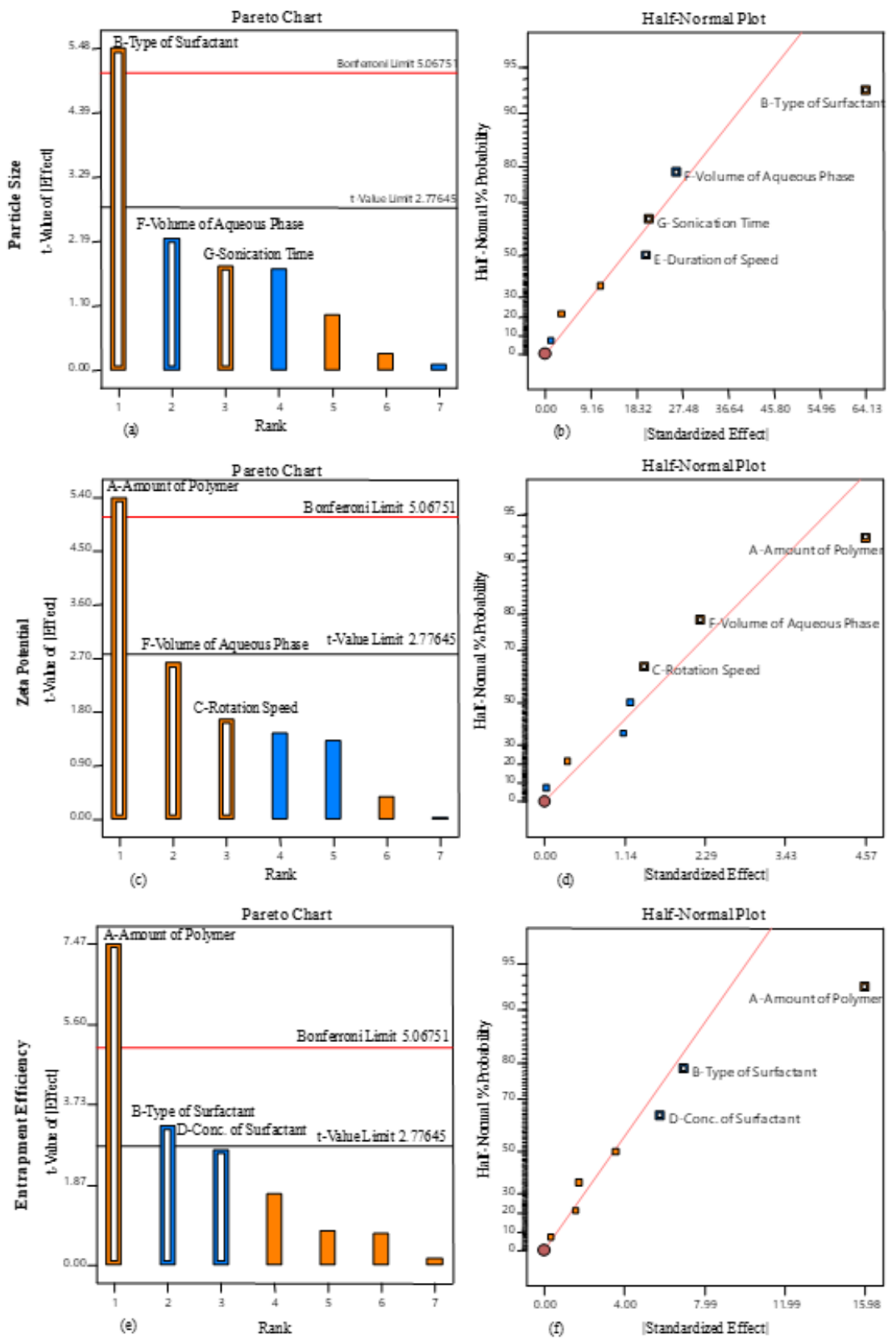

Figure 3

Pareto charts (a, c and e) and half-normal plots (b, $d$ and f) depicting the influential variables during the screening study of zeinNPs of MTX 

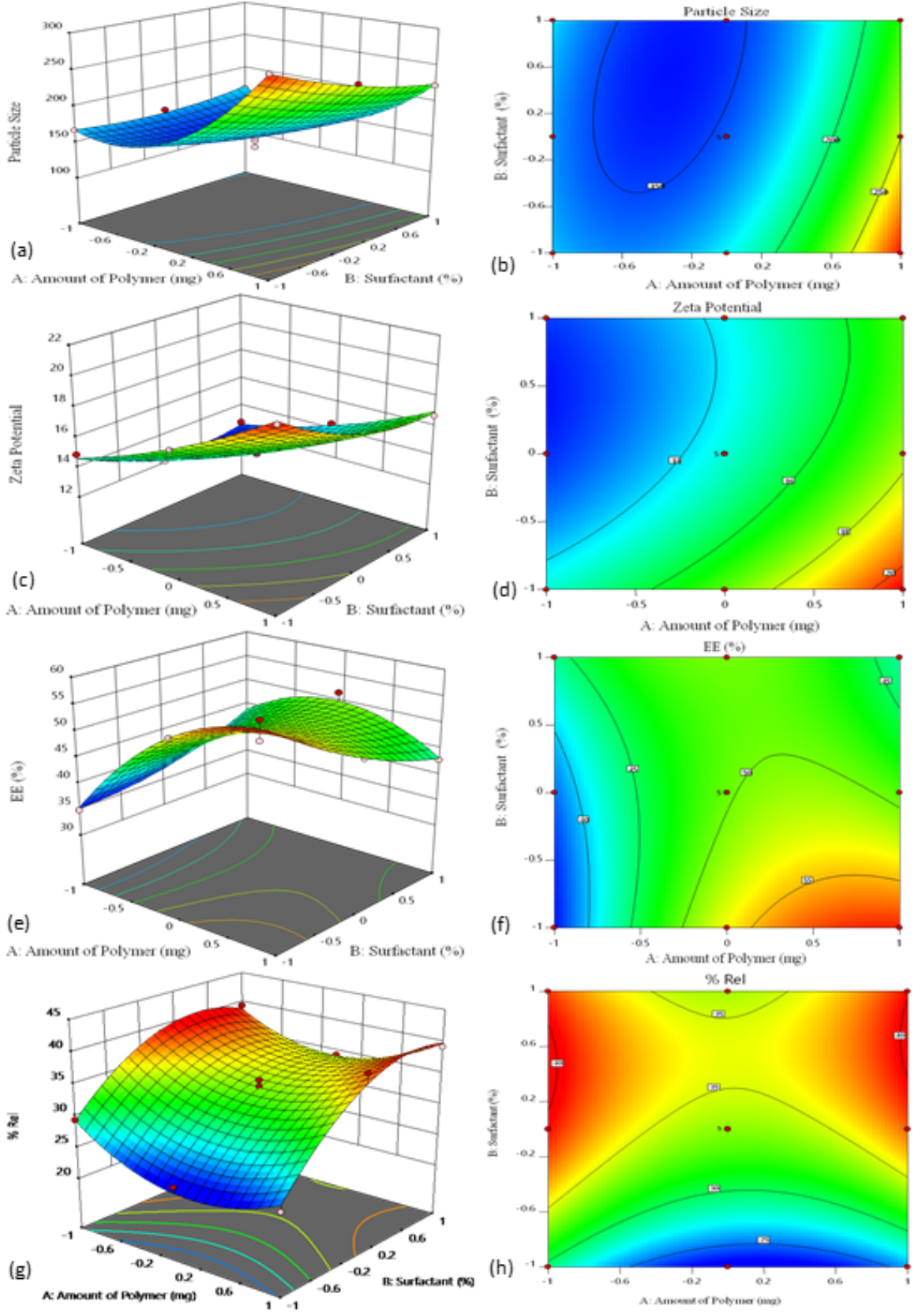

\section{Figure 4}

3D-response surfaces and 2D- contour plots for different CQAs, viz., particle size (a-b), zeta potential (c-d), \% EE (e-f), and cumulative $\%$ drug release $(\mathrm{g}-\mathrm{h})$ 


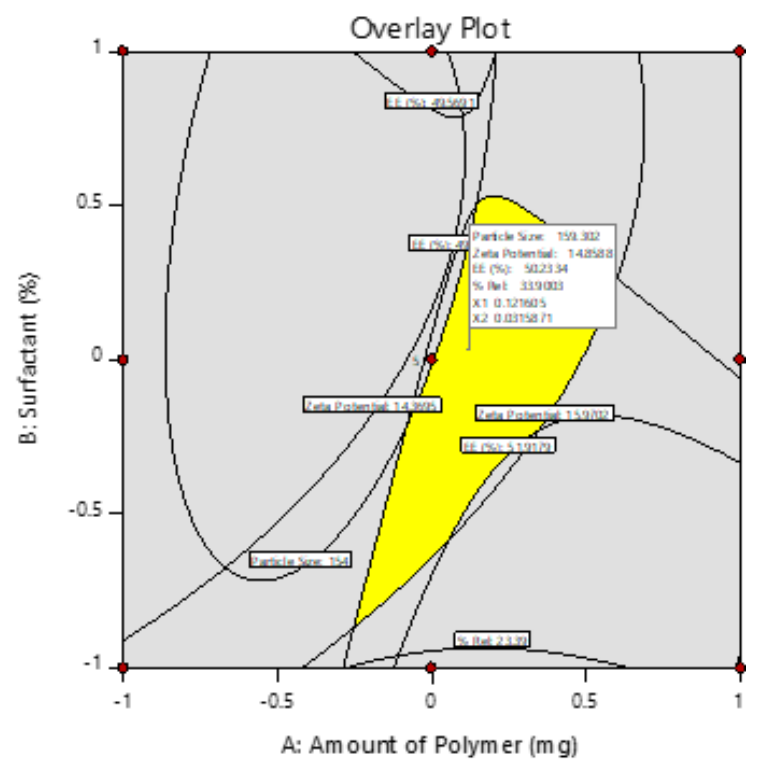

Figure 5

An overlay plot depicting the design space of the optimized formulation
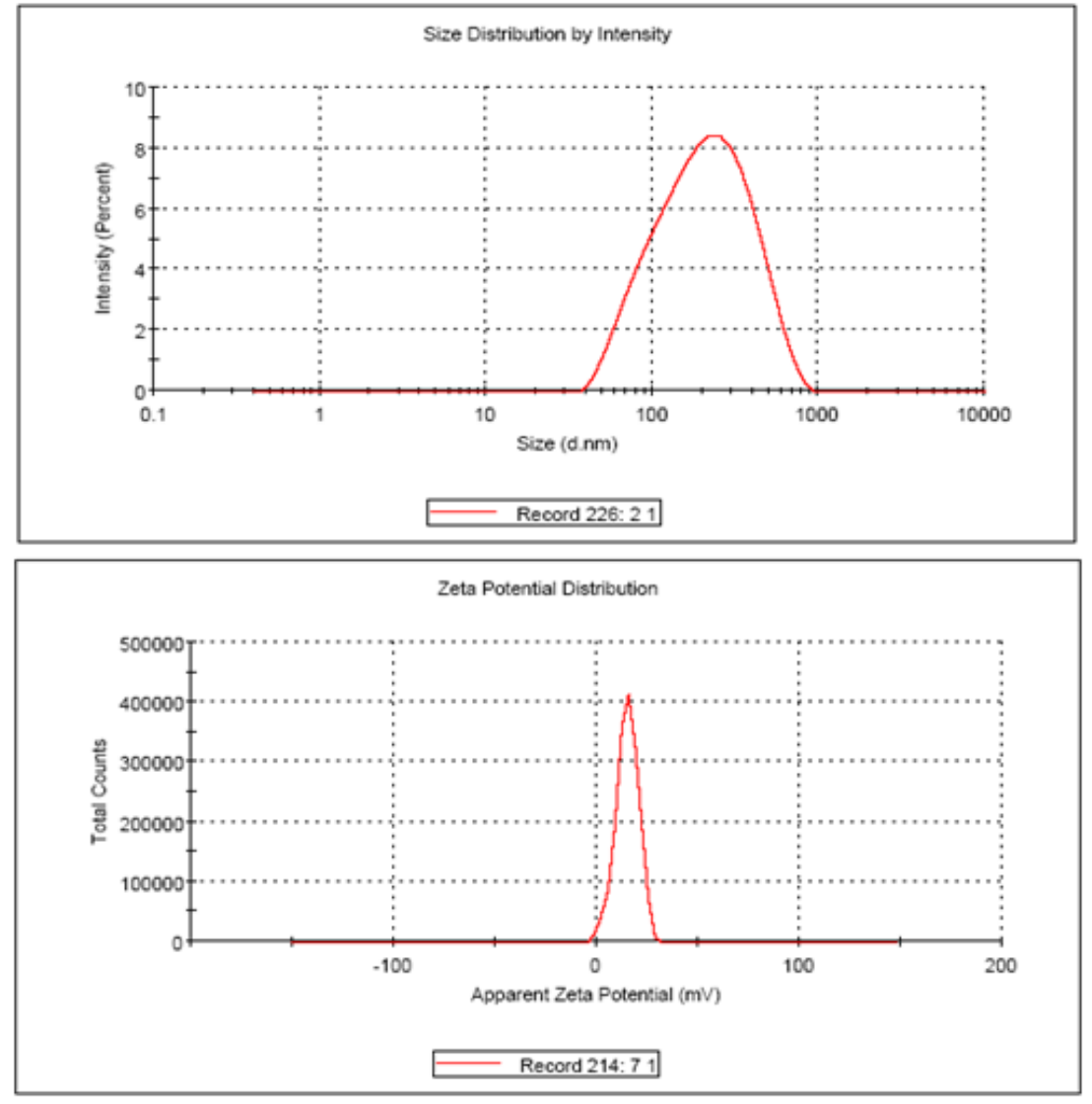

\section{Figure 6}

Photo-images of (a) particle size (b) zeta potential of the optimized zein nanoparticles 

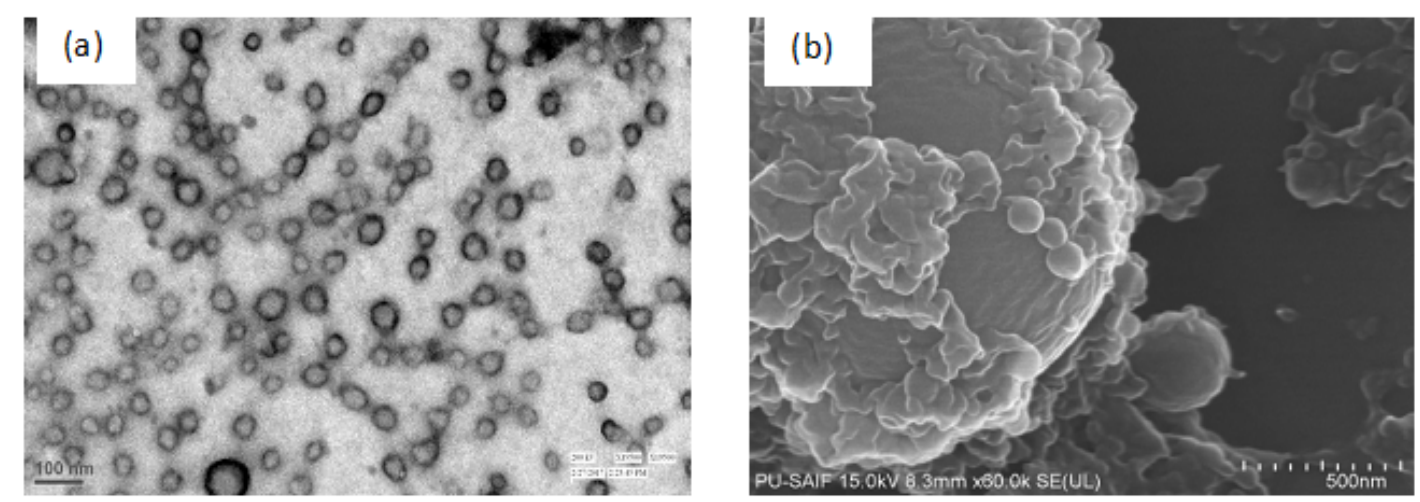

Figure 7

TEM and FESEM images of optimized zein nanoparticles

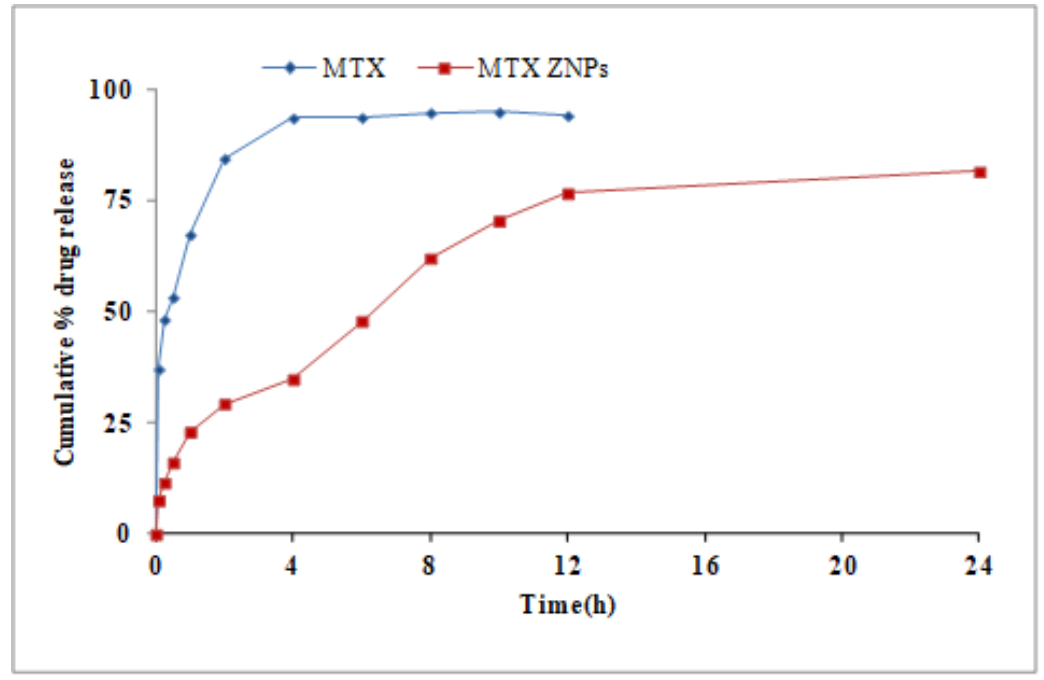

Figure 8

Cumulative release profiles of MTX and zein nanoparticles in phosphate buffer $\mathrm{pH} 7.4$

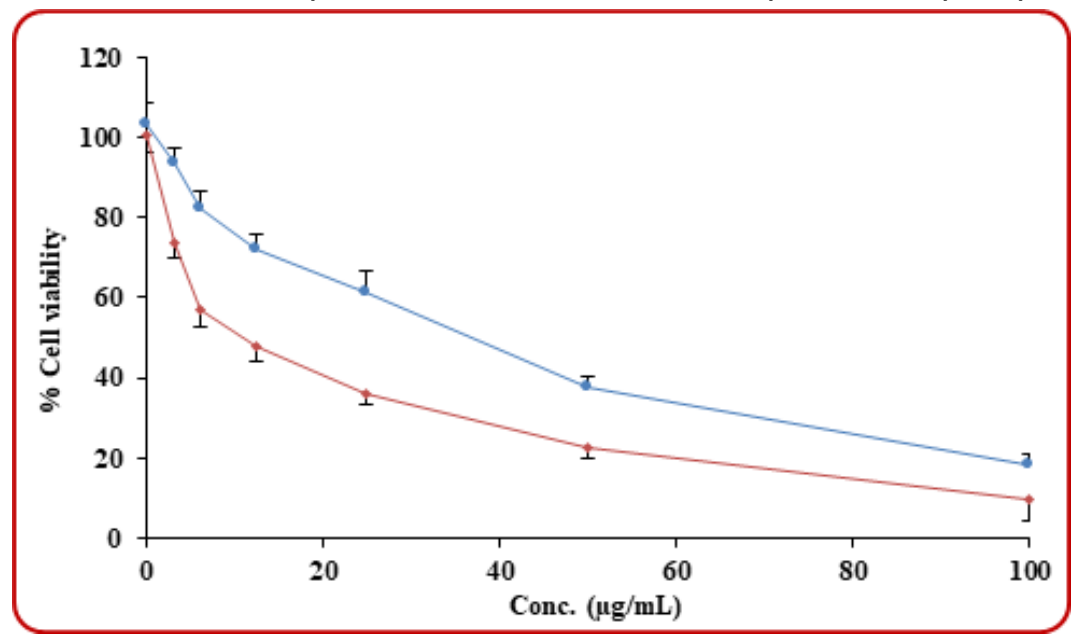

\section{Figure 9}

In vitro cell cytotoxicity profiles of MTX $(\bullet)$ and zein nanoparticles $(\diamond)$, performed on MCF-7 cells lines. Data are expressed as Mean \pm SD; $n=3$ 

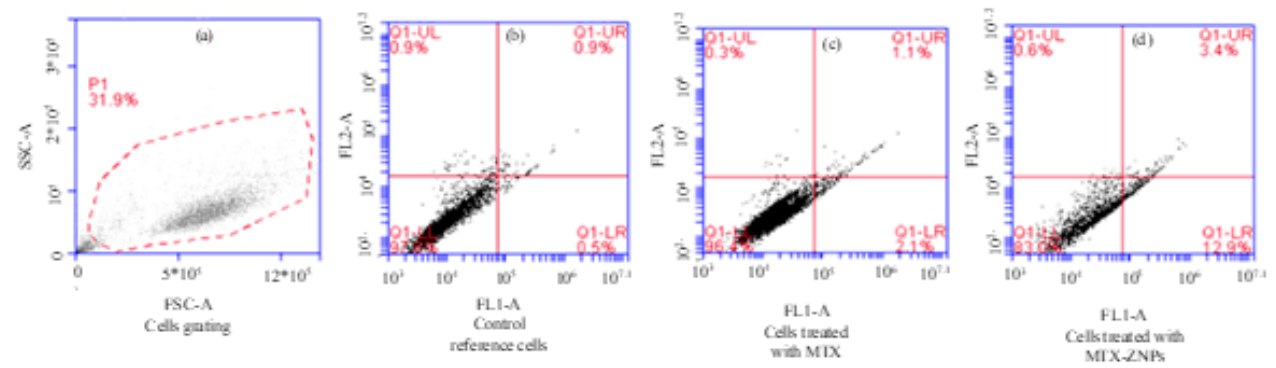

\section{Figure 10}

Apoptotic changes in plasma membrane of MCF-7 cells with concurrent staining using Annexin V-FITC/propidium iodide; (a) Gating of cells, (b) reference control cells, (c) cells treated with MTX, and (d) cells treated with zein nanoparticles
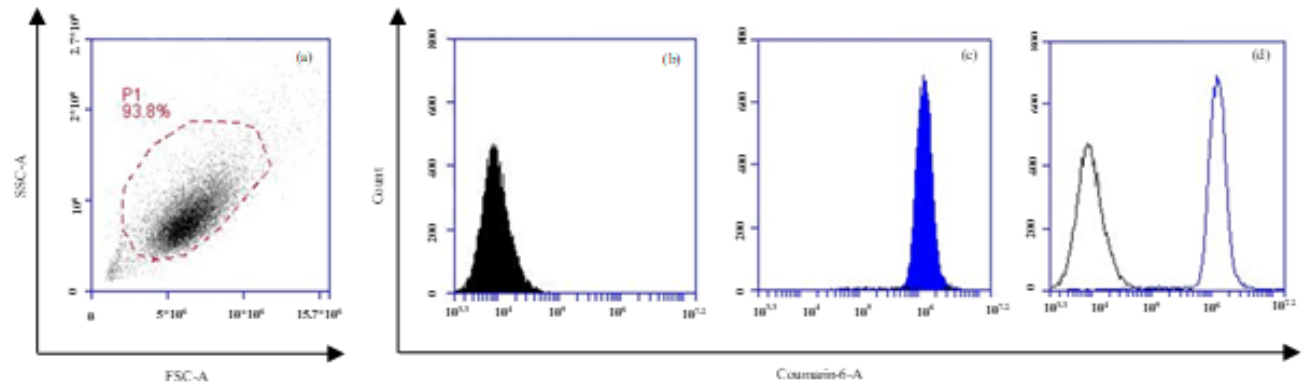

\section{Figure 11}

Cellular uptake study using Coumarin-6 (a) Gating of cells on FSC/SSC plot, (b) fluorescence intensity of courmarin-6 treated cells, (c) fluorescence intensity in coumarin-6 loaded nanoparticles treated cells, (d) an overlay plot of (b) and (c)

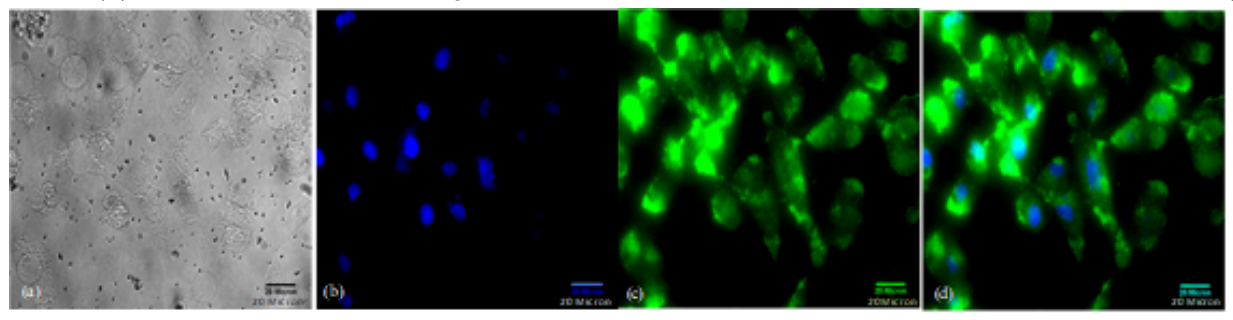

Figure 12

Qualitative cellular uptake of Coumarin-6 loaded zein nanoparticles (C6-zein-NPs) using CLSM (a) TD image of MCF-7 cells representing normal cells, (b) Cells treated with coumarin-6 (c) normal MCF-7 cells (d) Overlay images (b) and (c) showing localization of C6-zein-NPs in Caco-2 cells 


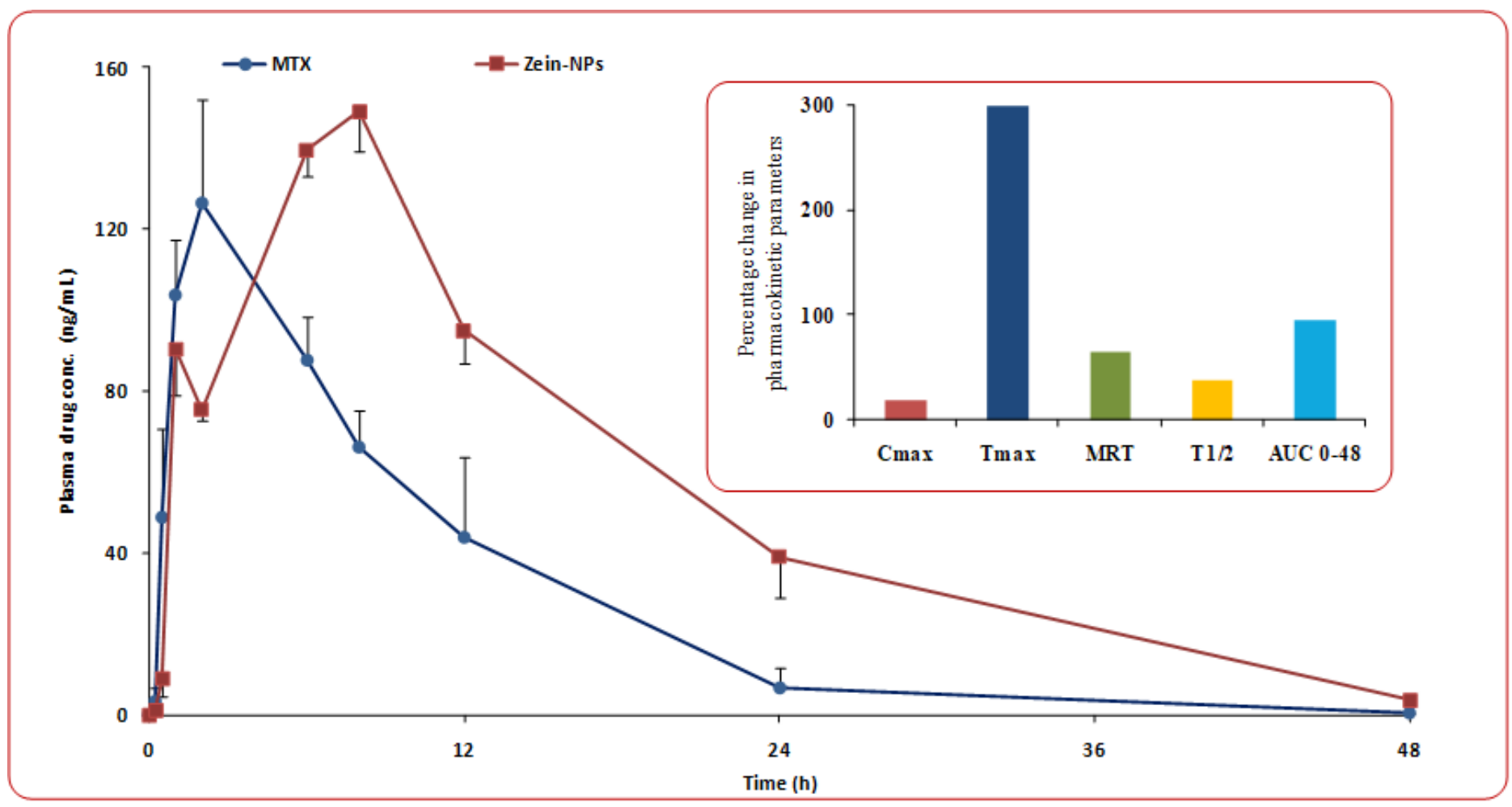

Figure 13

Plasma level profiles of MTX (๑) and zein nanoparticles ( ) at different time-points observed in rats. Data are expressed in Mean $+/-1$ SEM $(n=3)$. The corresponding inset depicts percent change in different pharmacokinetic parameters
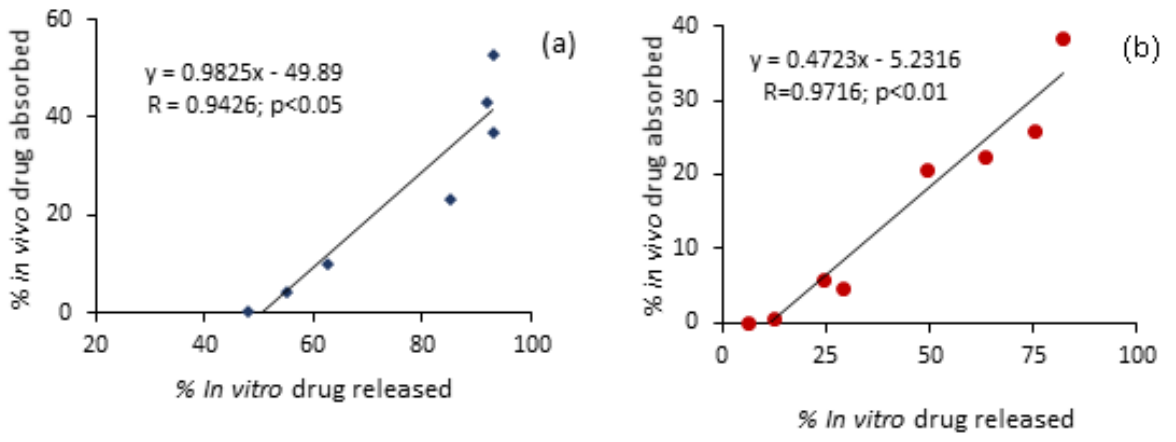

Figure 14

Establishment of point-to-point Level A correlations between the values of in vitro percent drug released and of in vivo percent drug absorbed; (a) MTX, and (b) zein nanoparticles of MTX

\section{Supplementary Files}

This is a list of supplementary files associated with this preprint. Click to download.

- SupplementaryZeinBSB2.docx

- Onlinefloatimage1.png 